Crosthwaite, P., Cheung, LML \& Jiang, F. (2017). Writing with attitude: Stance expression in learner and professional dentistry research reports. English for Specific Purposes, accepted, to appear.

\title{
Writing with attitude: Stance expression in learner and professional dentistry research reports
}

\begin{abstract}
Medical students often lack key skills in academic writing, yet good academic writing is often a pre-requisite for employment, promotion and enculturation into the profession. This article focuses on the rhetorical strategies used for the presentation of academic stance by student writers of dentistry research reports. Adopting a contrastive, corpus-based approach, we compare student writing with that of comparable professionally-written research reports for evidence of hedging, boosting, self-mention and attitude markers. Our findings indicate that professional reports exhibit a narrower set of linguistic devices than used by student writers, who tend to use a much wider range of the four stance feature types analysed for discussion of both others' and their own personal stance, both across whole texts and by section. We discuss pedagogical implications for ESP professionals working to more closely align student writing with that of professional norms.
\end{abstract}

Keywords: Stance; Contrastive interlanguage analysis; English for specific purposes; learner corpus; dentistry

\section{Introduction}

Successful academic texts are built not simply on the writers' plausible representation of external reality, but perhaps more importantly on their projection of authorial stance toward the issues they discuss, while persuading disciplinary readers of the relevance and value of their research. The ability to achieve these rhetorical ends is now acknowledged to be both a key feature of writing in the discipline and an important aspect of academic literacy (Hyland, 1999; Lancaster, 2016). Thus a large number of studies have examined how stance is conveyed through different linguistic means (e.g. Charles, 2004), across disciplines and genres (e.g. Hyland and Guinda, 2012), between student and expert writers (e.g. Hyland and Tse, 2005), and even along historical periods (e.g. Hyland and Jiang, 2016). Although Gross and Chesley (2012) and Yang et al. (2015) are among the few who have looked at the stance-making practice in medical prose, little attention has been given to medical research reports. Our focus in this paper is on the dentistry discipline, and how undergraduate students of dentistry grapple with this professional research genre. 
Crosthwaite, P., Cheung, LML \& Jiang, F. (2017). Writing with attitude: Stance expression in learner and professional dentistry research reports. English for Specific Purposes, accepted, to appear.

This study aims to highlight, via a corpus-based approach, how both professional practitioners and undergraduate students of dentistry epistemologically and rhetorically demonstrate the findings of research projects in a written report format, and how the metadiscourse used for these functions highlights students’ awareness of and engagement with disciplinary specificity of writing in dentistry. It is implied in this process that efforts spent on 'learning to write' in professional genres such as research reports are to entail the additional benefits of 'writing to learn', as students' adoption of rhetorical norms as part of the instruction and writing process enculturates them into professional practice. We begin by exploring how writers express epistemic and rhetorical values (namely the writer's presentation of stance) in their research reports, then describing how this process is shaped by disciplinary practice. We then outline the potential of the writing process for teaching and learning before presenting our contrastive analysis of stance features in learner and professional dentistry reports.

\section{Stance in academic writing: evidentiality, attitude and presence}

For students studying in medical fields, the vast majority of their time at university is spent training their technical skills so as to be able to perform complex procedures after graduation, both in terms of practical activities and extensive academic reading. However, one area of their university lives that students often neglect is their academic writing, with students from nonnative English speaking backgrounds at English-as-a-medium-of-instruction universities facing particular difficulties. To second (and even first) language users of academic English, academic writing is an 'alien form of literacy [...and] many students arriving at university think they have landed on Mars' (Hyland, 2016:246). 
Crosthwaite, P., Cheung, LML \& Jiang, F. (2017). Writing with attitude: Stance expression in learner and professional dentistry research reports. English for Specific Purposes, accepted, to appear.

While academic argument relies on a personal take on a claim or finding that matters to a discipline (Thompson and Hunston, 2000), stance is something of a catch-all yet elusive concept. For Biber (2006), stance expresses a writer’s ‘personal feelings and assessments', including 'attitudes that a speaker has about information, how certain they are about its veracity, how they obtained access to the information, and what perspective they are taking' (p. 87). The APPRAISAL theory (Martin and White, 2005) suggests writers position their stance through the employment of lexical resources for engagement (concerned with intersubjective positioning), attitude (concerned with the expression of emotions) and graduation (concerned with the strength of an evaluative position). More centrally, Hyland (2005) takes it as 'writer-oriented features of interaction', which have three main components: evidentiality, affect and presence (p.178). He further relates these to three important rhetorical questions that academic writers may bring to any statement about a text: how certain do I want to be about this?; what is my attitude towards it?; do I want to make myself prominent here? (Hyland, 2016, p. 248). In line with Biber (2006) and Hyland (2005), in this study, we see stance as the writer's expression of epistemic assessment, personal attitudes, and self-presence, by means of hedges and boosters, attitude markers and self-mentions.

Hedges, 'words or phrases whose job it is to make things fuzzier' (Lakoff, 1972: 195), allow the writer to express his or her lack of commitment to the certainty of the information given, while boosters allow writers to express their confidence about the validity of a proposition (Holmes, 1988; Hu and Cao, 2015; Hyland, 2005). Hedges and boosters are not only crucial in academic discourse but are also seen as a central rhetorical device in science discourse to gain communal adherence to knowledge claims and build interpersonal solidarity with readers (Hyland, 1999; Lancaster, 2016). Although attitudinal markers and self-mentions project writers' explicit 
Crosthwaite, P., Cheung, LML \& Jiang, F. (2017). Writing with attitude: Stance expression in learner and professional dentistry research reports. English for Specific Purposes, accepted, to appear.

presence and effectuate affective persuasion, they are not highly expected in scientific writing, which may privilege cloaking authors as humble servants to scientific methods (Biber, 2006; Hyland, 2005; McGrath, and Kuteeva, 2012). Hedges, boosters and attitudinal markers may sometimes be based on shared implicit assumptions based on tacit knowledge between readers and writers, particularly in scientific texts (Thompson and Hunston, 2000), but they are most explicitly signalled by lexical verbs (e.g. suggest, show, agree), modal verbs (e.g. could, must), adjectives (e.g. likely, undisputed, important), adverbs (e.g. perhaps, undoubtedly, surprisingly), and nouns (e.g. possibility, certainty, advantage).

Although these four elements help to concretise the ways that writers intrude to project their authorial stance as to the material and audience, we must be simultaneously aware that authors' self-representations are constrained by culturally/disciplinarily available options (Bruce, 2016; Charles, 2004; Hu and Cao, 2015; Hyland, 1999, 2005). Epistemic assessment is found to be more commonly used than attitudinal affect in academic texts (Thompson and Hunston, 2000), but in Gross and Chesley (2012)'s study, medical experts reduce the frequency of hedges used to persuade professional peers that what is said is objective truth, and to align with the industrysponsored biomedical research community. Aull and Lancaster (2014) noted 'a general trend of more developing academic writers using more boosters and fewer hedges' (2014, p. 162), and professional medical writers use epistemic (modal) references in order to promote implicit / explicit objective orientations (Yang et al., 2015). Thus any stance not only represents the writer's own individual position, but it is also a choice which reflects the epistemological beliefs and values of a community.

Literature also shows that although writers in hard sciences tend to offer less personal interpretations than their peers in soft knowledge fields, they do step in and project interactional 
Crosthwaite, P., Cheung, LML \& Jiang, F. (2017). Writing with attitude: Stance expression in learner and professional dentistry research reports. English for Specific Purposes, accepted, to appear.

positioning or disguise their personal involvement at critical points to make their readers find what they said trustworthy, plausible and persuasive (Charles, 2004; Hyland, 2005; McGrath and Kuteeva, 2012). Basturkmen (2012) found that dentistry authors persistently evaluated the results in the discussion section to 'register their opinions of certain results' and 'flag the importance or reliability of results’ (Basturkmen, 2012, p. 142). Similarly, Salager-Meyer (1994) has reported that the discussion section of medical reports is the most heavily rhetorical division, where authors more often ‘speculate, argue, contrast, and extrapolate from the described results’ (1994, p. 163) and thus with this invested interactional viewpoint highlight the 'fertility' of the current work. However, she also noted that in the methods section regarding obtaining of the data, authors reduce their personal investment to the largest extent (Salager-Meyer, 1994, p. 161).

In summary, stance options are therefore constrained by the rhetorical expectations of the discourse, by the writers' intended purpose, and the nature and strength of the claim(s) the writers wish to make (Swales, 1990; Taavitsainen, 2015; Vihla, 1999). Informed by prior investigations (e.g. Hyland and Tse, 2005; Lancaster, 2014; Nesi and Gardner, 2012), we see the need to examine how dentistry students handle this stance-making practice within the discipline compared with disciplinary professionals.

\section{Enculturation into the profession - English in the (dentistry) discipline}

The medical profession is one where universities and academia have a significant role to play in advancing medical knowledge via published works that are disseminated to professionals worldwide. As the world becomes more globalized, English becomes increasingly important as a tool for dentists to treat foreign patients and to communicate with peers, policy makers and other service providers within the discipline. Opportunities for promotion in the medical field are often tied to the number and quality of academic publications a medical professional has, and 
Crosthwaite, P., Cheung, LML \& Jiang, F. (2017). Writing with attitude: Stance expression in learner and professional dentistry research reports. English for Specific Purposes, accepted, to appear.

such publications enable practitioners to contribute to their field (Pololi, Knight and Dunn, 2004). There is thus a great need for would-be dentists to develop discipline-specific writing skills alongside the development of their skills in dentistry.

A central distinction currently in favour with the literature on writing and pedagogy is that of the role of writing in the learning process, namely that of 'learning to write' and 'writing to learn' (Boughey, 1997). For the former, Jones, Turner and Street (1999) suggest that in rethinking higher education and its writing practices, epistemology, identity and power are the primary concerns. Students should be able to consider and refine their own knowledge, voice and position through their writing, determine where they stand, and discover how they can contribute to the development of the wider professional field, while meeting the expectations of their course tutors and academic institutions via well-written academic texts. However, in terms of such writing, differences between students', tutors' and institutions’ perceptions of student and professional texts lead to ‘faculty and student frustration’ (Jones, Turner and Street, 1999:xviii), and teachers and students worry about the gap between what they see and produce for classroom assignments, and the type of writing used in the workplace (Kumpf and Emanuel, 1996). Tutors complain about the distance between student production and the professional texts used as exemplars on their courses, while often missing the opportunities for learning to write that might have arisen either during the production of the texts themselves (in the form of metacognition or collaborative writing practices), or following such production (in the form of corrective feedback or changes to pedagogy). In terms of writing to learn, one of the stated aims of the dental curriculum used in the context of the present study is to produce students and ultimately dentists who are skilled communicators in an evidence-based environment, given that dentistry is a professional field that has close ties with problem-based learning (PBL). A high level of 
Crosthwaite, P., Cheung, LML \& Jiang, F. (2017). Writing with attitude: Stance expression in learner and professional dentistry research reports. English for Specific Purposes, accepted, to appear.

English-language ability is required to allow dentistry students to understand the complexities of disciplinary literacy in joining a professional community and, specific to writing to learn, to participate in active trials with real patients. Yet information is lacking regarding the effectiveness of English education for dentistry, particularly in Asia (Morse and Nakahara, 2001), and it seems that most dentistry students in Asia have little of their core training in English. For instance, in Japan’s six-year undergraduate dentistry programme, only general English for academic purposes featured in the curriculum, and while some institutes did introduce special 'Dental English’ training in their curricula, most students 'are unclear about what exactly constitutes Dental English’ (Morse and Nakahara, 2001: 168). Since then, a core curriculum for dental English education has been proposed in Japan to offer more specific English training in medical and dental terminology and patient- and inter- and intra-professional interaction (Rodis, et al, 2014). Yet this Japanese example appears to be an isolated case, and there is still a lack of evidence in the literature regarding whether such training eventually leads to writing that appears to follow the rhetorical and attitudinal norms of the profession in which the students are to become enculturated, and whether training in writing leads to opportunities for learning about the discipline.

\section{Rationale and scope of the present study}

This research focuses on undergraduate students of dentistry at a university in Hong Kong. The writing centre of the university in question has devised an English course for dentistry students, with discipline specificity resting on the idea of 'teaching the literacy skills which are appropriate to the purposes and understandings of particular communities' (Hyland, 2002: 385).

As the sole provider of dental education in Hong Kong and an English-medium university with a full inclusion of PBL in its six-year curriculum, the Faculty of Dentistry demands that students 
Crosthwaite, P., Cheung, LML \& Jiang, F. (2017). Writing with attitude: Stance expression in learner and professional dentistry research reports. English for Specific Purposes, accepted, to appear.

be proficient in English (TOEFL paper-based score of not less than 550). To support the Faculty's yearly intake of approximately 70 students, discipline-specific English support is targeted at the fifth-year level. This English-in-the-Discipline (ED) course is a compulsory 6credit course for fifth-year dentistry students to develop their research report writing skills. The course is contextualized within and integrated into the study of public health academic writing, realised in the form of a full research report as an outcome of the dentistry students' Community Health Project (CHP), a compulsory module of the dental curriculum. Since 1984, through these projects, dentistry students from different cohorts have obtained a better understanding of Hong Kong's specific oral health conditions and oral health care provision. Since the CHP requires dentistry students to complete a year-long group study concerning a dental public health issue (making considerable demand of their English language skills), a general comment made by supervisors is that their students need training in recognising and understanding how to convey the results of their research according to the English-language norms of the target disciplinary field. Thus, the stance features outlined in the above sections would be important for dentistry students to learn in order to understand the inextricable connection between language and content in presenting findings of their research, and to increase their awareness of such dovetailing in the context of Hong Kong and beyond.

Given the above, it is apparent that investigating professional and learner writers' presentation of stance in dentistry research reports will allow us to determine the extent to which disciplinespecific English-language training results in learner enculturation into the dentistry field as evidenced by the frequency and wording of the stance features present. With this in mind, the following research questions are explored: 
Crosthwaite, P., Cheung, LML \& Jiang, F. (2017). Writing with attitude: Stance expression in learner and professional dentistry research reports. English for Specific Purposes, accepted, to appear.

1) How do professional and learner writers manage the presentation of stance in their respective dentistry research reports?

2) To what extent do student writers of PBL research final-year dentistry reports demonstrate evidence of enculturation into the dentistry profession, as evidenced by their use of stance features when compared against that of professionally written research papers?

3) What are the implications for pedagogy regarding the outcome of the analysis of stance features across learner PBL research reports and those of professionally-written research papers?

\section{Data and Method}

5.1. A corpus-based approach to learner and professional stance analysis - Contrastive Interlanguage Analysis

This paper adopts a corpus-based approach to the analysis of stance in learner and professional texts. By 'corpus', we mean a collection of searchable, electronic texts that can be analysed for frequency, lexical and morphosyntactic features, and that can be annotated for the elements of stance under investigation. Notably, studies of academic corpora have sought to emphasize the importance of rhetorical practices in academic persuasion across a wide range of specific academic disciplines (e.g. Hyland, 2005, Hyland and Tse, 2005). There has also been a growing body of corpus applications within the field of English for specific purposes and language pedagogy. Within clinical disciplines, while much has been studied about medical discourse using corpus-based analysis (see for example Marco, 2000; Williams, 1996), little empirical information is currently available about the language of dentistry. One notable exception is Carlson (2000), who compiled a corpus of 1,400 dental research abstracts to investigate word 
Crosthwaite, P., Cheung, LML \& Jiang, F. (2017). Writing with attitude: Stance expression in learner and professional dentistry research reports. English for Specific Purposes, accepted, to appear.

frequency and word collocations in dental English. Another exception is Millar and Budgell (2008), who used an existing corpus of public health journal articles to identify the distinctive lexical and syntactic conventions of the public health literature. However, the full spectrum of written communication in dentistry that can be reflected in research articles remains a worthwhile but unexplored area, and little attention had been paid to how such research findings could be effectively applied in language pedagogy or curriculum development. Therefore, the findings from our professional dentistry corpus can allow learners to understand the complexities of disciplinary communication in the L1 context, and can enhance dentistry students' communicative competence in research report writing.

When comparing learner and professionally written corpora, the prominent methodology is that of Contrastive Interlanguage Analysis (CIA), as part of an Integrated Contrastive Model (Gilquin, 2000; Granger, 1996, 2015). CIA is an attempt to 'discover the features of nativeness and non-nativeness of learner language by comparing it with native language' (Gilquin, 2000:95). Criticisms of the original CIA were the 'comparative fallacy' (Bley-Vroman, 1989) of comparing L1-L2 data under identical terms, and 'the issue of the norm', i.e. the idea of L1 or ‘native’ English as a monolithic ideal in spite of near-native varieties and areas where English is spoken as a lingua franca. The CIA ${ }^{2}$ model (Granger, 2015) overcomes these problems by considering both expert or learner corpora as varieties, where 'reference language varieties' may be compared against 'interlanguage varieties', either of which can be set according to dialectic or diatypic variables. Information on the two corpora is provided in the following sections. 
Crosthwaite, P., Cheung, LML \& Jiang, F. (2017). Writing with attitude: Stance expression in learner and professional dentistry research reports. English for Specific Purposes, accepted, to appear.

\subsection{Professional Dentistry Corpus - Community Dental Health}

This 500,000-word corpus of scholarly writing comprises recent research articles published in a key domain-specific journal - Community Dental Health - between 2010 and 2012. This journal is selected because it is accessible in electronic form, licensed by our institute's library, and conforms to standard American and British English. Most importantly, it is a key journal publishing on a wide spectrum of public health issues in dentistry that are highly relevant to the ED course. There are four issues in each year with ten research articles per issue. A total of 156 research articles were selected during the period of 2010 to 2012. Editorials, news, reviews and commentaries from the selected issues of this journal are not included because they do not specifically reflect the genre of research report writing. While there are no strict constraints on the use of self-mentions and other overt stance features in the journal's style sheet, the journal did impose suggested length constraints of 3,000 words, and the journal website reminds authors to be consistent with clarity of communication. While this might have an overall impact on the use of stance expressions with writers mindful of the need to write as concisely as possible, this journal was selected as the best professional representation of the kind of community-focused research our students were undertaking. Permission to use this data was granted by the journal editor. This corpus of professional, published writing provides a valuable and reliable benchmark regarding the characteristics, conventions, and stylistic features of stance in community-focused dentistry writing.

\subsection{Learner Corpus of Dentistry Reports}

The largest change in the dental curriculum in the U.S. between 2002 and 2009 was the increased proportion of schools creating community-based experiences for students, a method of 
Crosthwaite, P., Cheung, LML \& Jiang, F. (2017). Writing with attitude: Stance expression in learner and professional dentistry research reports. English for Specific Purposes, accepted, to appear.

experiential learning with the mission to offer dental care to the community (Crawford and Johnson, 2007). This striking change reflects that dentists (or dentistry students in preparing for their professions) require community-based clinical experience. Faced with this new demand, the institute in the present study shifted its focus in the fifth year dental curriculum to 'complex, integrated patient care across the years and communities’ (Faculty of Dentistry, 2015). The 9credit module on CHPs provides dentistry students with experience of participating in projectbased research activities. Here, 'knowledge is synthesized and transferred through the training process of planning, organizing, conducting, and presenting a community health project'. (ibid)

The learner corpus data is taken from a collection of the institute's fifth-year dentistry students' PBL research reports required for the CHPs. This 500,000-word collection contains all L2 group research reports produced between 1984 and 2010. While students have produced these reports since 1984, the ED training began in 2002. As the major assessed work of the CHPs, these reports are produced in small groups of 6-8 dentistry students and provide a representative sample of university writing in the public health discipline. Each academic year, there are approximately 6 groups of dentistry students. The reports are accessible in electronic form and are licensed by the institute's library, and generally carefully proofread and well-written (all texts analysed received a passing grade). This collection has been used in the past to inform dentistry students of the type of writing they need to undertake for their CHPs and the norms of the CHP discourse community.

The handbook for the CHP suggests that projects must be relevant to HK, of current interest, manageable in terms of time and resources, of interest to the whole group of writers, and within the broad field of dental public health. The handbook advises students to include an abstract, 
Crosthwaite, P., Cheung, LML \& Jiang, F. (2017). Writing with attitude: Stance expression in learner and professional dentistry research reports. English for Specific Purposes, accepted, to appear.

introduction including aims and objectives, materials and methods, results, discussion, conclusion and recommendations sections, in that order. The handbook offers no details specific to the language used in writing the projects. Student groups were allocated 'project advisors' to oversee their work, but these were not language teachers, but members of the faculty of dentistry, who were considered unlikely to provide much in the way of feedback on language issues, including that of stance presentation.

\subsection{Annotation and analysis}

The data for the two corpora were converted into plain text files, then into a searchable corpus using UAMCorpustool (O’Donnell, 2008). UAMCorpustool allows for both manual and automatic annotation using Corpus Query Language expressions to bring up all instances of a given word or phrase, which can then be annotated simultaneously. The choice of items matches that of Hyland (2000), which is a general list of common stance devices. This list was chosen due to its non-disciplinary specific nature, rather than compiling a list of dentistry stance features from the professional corpus before comparing their occurrence with the learner data. Doing the latter would firstly risk committing the comparative fallacy, and secondly risk omitting any nondiscipline specific devices used in the learner data from the analysis. The full list of individual linguistic items annotated is found in the Appendix. Each annotated occurrence of these items was then double-checked by the first author and a research assistant of near-native English proficiency along a 9-word context concordance line to ensure that each occurrence fulfilled its stated function (e.g. if a booster such as 'clear' was preceded with 'not', leaving this an instance of a hedging device). This approach follows the suggestion of Dagneaux, Denness and Granger (1998) in that 'efficiency is increased' if the annotator has both a high knowledge of English grammar and the L1 mother tongue of the interlanguage variety to be analysed (p.165). 
Crosthwaite, P., Cheung, LML \& Jiang, F. (2017). Writing with attitude: Stance expression in learner and professional dentistry research reports. English for Specific Purposes, accepted, to appear.

For analysis of cross-corpora frequencies, due to differences in corpus sizes, the raw frequencies of the annotated items were converted into a normalised frequency per 1,000 words in UAMCorpustool. The frequencies for each file in the corpus were then exported to an Excel document then converted into an SPSS-ready file (v.20) for statistical analysis.

For analysis of wordings, UAMCorpustool was used to generate wordlists from both learner and dentistry corpora containing raw frequency information, which was then entered into the loglikelihood calculator (Rayson, 2016, http://ucrel.lancs.ac.uk/llwizard.html) alongside information regarding the total corpus size to determine the log-likelihood value $(L L)$ of each wording (i.e. a contingency value representing potential significant differences between target wordings and non-target wordings in two [or more] corpora). Significance values of $p<0.001$ are given for $L L$ values of greater than 10.83, and significance values of $p<0.0001$ are given for $L L$ values of greater than 15.13. Effect sizes for log-likelihood are also provided, following the Bayes Factor (BIC) measure (Wilson, 2013) which is a measure of strength of significant LL $p$ values in terms of degrees of evidence against the null hypothesis (i.e. the LL $p$ value has no measurable effect), with scores varying between 0-2: low effect, 2-6: positive evidence against the null hypothesis (H0), 6-10: strong evidence against H0, > 10: very strong evidence against H0. For negative scores, the BIC scale is read as 'in favour of' instead of 'against' the H0, and so wordings with significant LL values but negative BIC effect sizes are not included in the results.

We also attempted to correlate (via Pearson R) the date the learner reports were produced with the stance features involved, in order to determine if there were any potential impact of instructional change over the time period. While the CHP data dates back to 1984, the ED 
Crosthwaite, P., Cheung, LML \& Jiang, F. (2017). Writing with attitude: Stance expression in learner and professional dentistry research reports. English for Specific Purposes, accepted, to appear.

training began in 2002, and so any positive correlation between time and stance feature might be suggestive of an impact of instruction.

\subsection{Corpus Statistics}

Table 1 contains statistical information about each corpus.

Table 1 - Corpus size (whole texts, excluding references and appendices)

\begin{tabular}{lccll}
\hline Corpus & Texts & Words & Av. text length & Annotated items \\
\hline Dentistry learner corpus & 133 & 525140 & 3948.42 & $\begin{array}{l}\mathrm{H}=8659, \mathrm{~B}=3898, \\
\mathrm{SM}=4093, \mathrm{AM}=1167\end{array}$ \\
& & & & $\mathrm{H}=4879, \mathrm{~B}=2296$, \\
Professional dentistry & 156 & 364,680 & 2337.69 & $\mathrm{SM}=744, \mathrm{AM}=614$ \\
\begin{tabular}{l} 
Corpus \\
\hline
\end{tabular} & & &
\end{tabular}

(H=Hedges, B=Boosters, SM=Self-mentions, AM=Attitude Markers.)

Despite having the smaller number of texts, the learner dentistry corpus is the larger corpus, with the average text length almost double that of the professional corpus. References and appendices were stripped from the word counts. Table 2 shows the two corpora by section. 
Crosthwaite, P., Cheung, LML \& Jiang, F. (2017). Writing with attitude: Stance expression in learner and professional dentistry research reports. English for Specific Purposes, accepted, to appear.

Table 2 - Corpus size (by section)

\begin{tabular}{llll}
\hline Corpus & Words & $\begin{array}{l}\text { Av. } \\
\text { Section } \\
\text { Length }\end{array}$ & Annotated items \\
\hline $\begin{array}{l}\text { Dentistry learner corpus } \\
\text { Abstract }\end{array}$ & 33929 & 255.10 & $\mathrm{H}=379, \mathrm{~B}=262, \mathrm{SM}=105, \mathrm{AM}=17$ \\
$\begin{array}{l}\text { Introduction } \\
\text { Method }\end{array}$ & 71306 & 536.13 & $\mathrm{H}=1213, \mathrm{~B}=514, \mathrm{SM}=358, \mathrm{AM}=117$ \\
$\begin{array}{l}\text { Results } \\
\text { Discussion }\end{array}$ & 99294 & 746.57 & $\mathrm{H}=677, \mathrm{~B}=248, \mathrm{SM}=777, \mathrm{AM}=120$ \\
Limitations & 157641 & 1185.27 & $\mathrm{H}=2439, \mathrm{~B}=1191, \mathrm{SM}=376, \mathrm{AM}=312$ \\
$\begin{array}{l}\text { Conclusion } \\
\text { Recommendations }\end{array}$ & 130717 & 982.83 & $\mathrm{H}=3288, \mathrm{~B}=1371, \mathrm{SM}=1349, \mathrm{AM}=420$ \\
& 3013 & 22.65 & $\mathrm{H}=192, \mathrm{~B}=11, \mathrm{SM}=77, \mathrm{AM}=8$ \\
$\begin{array}{l}\text { Professional dentistry } \\
\text { Corpus }\end{array}$ & 16383 & 123.18 & $\mathrm{H}=269, \mathrm{~B}=141, \mathrm{SM}=131, \mathrm{AM}=35$ \\
$\begin{array}{l}\text { Abstract } \\
\text { Introduction }\end{array}$ & 12857 & 96.66 & $\mathrm{H}=200, \mathrm{~B}=75, \mathrm{SM}=152, \mathrm{AM}=23$ \\
$\begin{array}{l}\text { Method } \\
\text { Results }\end{array}$ & & & \\
$\begin{array}{l}\text { Discussion } \\
\text { Limitations }\end{array}$ & 29823 & 224.23 & $\mathrm{H}=252, \mathrm{~B}=131, \mathrm{SM}=105, \mathrm{AM}=17$ \\
$\begin{array}{l}\text { Conclusion } \\
\text { Recommendations }\end{array}$ & 51422 & 386.63 & $\mathrm{H}=714, \mathrm{~B}=318, \mathrm{SM}=29, \mathrm{AM}=77$ \\
& 80721 & 606.92 & $\mathrm{H}=504, \mathrm{~B}=180, \mathrm{SM}=161, \mathrm{AM}=99$ \\
& 74161 & 557.60 & $\mathrm{H}=759, \mathrm{~B}=585, \mathrm{SM}=55, \mathrm{AM}=116$ \\
& 103543 & 778.51 & $\mathrm{H}=2061, \mathrm{~B}=847, \mathrm{SM}=324, \mathrm{AM}=228$ \\
& 8023 & 60.32 & $\mathrm{H}=69, \mathrm{~B}=55, \mathrm{SM}=54, \mathrm{AM}=13$ \\
& 11356 & 85.38 & $\mathrm{H}=214, \mathrm{~B}=115, \mathrm{SM}=28, \mathrm{AM}=23$ \\
& 5631 & 42.33 & $\mathrm{H}=88, \mathrm{~B}=35, \mathrm{M}=12, \mathrm{AM}=17$ \\
& & &
\end{tabular}

(H=Hedges, B=Boosters, SM=Self-mentions, AM=Attitude Markers.)

There are two major points of interest in relation to the sizes of the learner and professional corpora in Table 2. The first is that, while small in each corpus, the limitations sections found in the professional dentistry corpus are three times longer than those found in the learner dentistry corpus. As the limitations section is a section where hedging the findings of the study would potentially be most likely to occur, it is apparent that the learner writers do not tend to focus on the limitations of their studies, perhaps because the research reports are assessed and they wish to appraise the importance of their research, thus choosing not to address the limitations of their studies in detail. The second point of interest is that the recommendations sections of texts in the learner corpus are almost three times longer than those of the professional corpus. Since the focus of CHPs is on addressing public health-related issues at a community level, it is likely that 
Crosthwaite, P., Cheung, LML \& Jiang, F. (2017). Writing with attitude: Stance expression in learner and professional dentistry research reports. English for Specific Purposes, accepted, to appear.

the learner writers tend to put more emphasis on the recommendations of their studies, because they are committed to create an impact on Hong Kong’s oral health conditions and provision of community oral health services as required in the project guidelines.

\section{Results}

\subsection{Cross-corpus comparison across whole texts}

Table 3 shows the cross-corpora distribution of stance devices between the two corpora. To correct for multiple testing (avoiding ‘data dredging' / 'data fishing', where multiple tests can lead to false significance, see Young and Karr, 2011), an alpha value of 0.0125 (for 4 tests) was used to ascertain the significance of the Mann-Whitney U comparison, with Holm-Bonferroni correction on the $p$ values. As non-parametric statistics were performed, the median/absolute deviations are reported instead of the mean/standard deviations.

Table 3 - Cross-corpora comparison of stance markers.

\begin{tabular}{lllc}
\hline \hline Feature & Mean/AD per 1,000 words & Mann-Whitney & $\begin{array}{c}\text { Effect } \\
\text { (Pearson R) }\end{array}$ \\
\hline Hedges & $\begin{array}{l}\text { Dent. Learner, } \mathrm{M}=9.86, \mathrm{AD}=2.38 \\
\text { Dent. Prof., } \mathrm{M}=6.85, \mathrm{AD}=1.91\end{array}$ & $\mathrm{U}=4,907, \mathrm{t}=-7.72, p<.001$ & $r=-0.454$ \\
Boosters & $\begin{array}{l}\text { Dent. Learner, } \mathrm{M}=4.44, \mathrm{AD}=1.08 \\
\text { Dent. Prof. } \mathrm{M}=3.35, \mathrm{AD}=0.88\end{array}$ & $\mathrm{U}=6,057, \mathrm{t}=-6.09, p<.001$ & $r=-0.359$ \\
$\begin{array}{l}\text { Self- } \\
\text { mentions }\end{array}$ & $\begin{array}{l}\text { Dent. Learner, } \mathrm{M}=4.24, \mathrm{AD}=2.17 \\
\text { Dent. Prof. } \mathrm{M}=0.67, \mathrm{AD}=0.45\end{array}$ & $\mathrm{U}=2,312, \mathrm{t}=-11.38, p<.001$ & $r=-0.670$ \\
$\begin{array}{l}\text { Attitude } \\
\text { markers }\end{array}$ & $\begin{array}{l}\text { Dent. Learner, } \mathrm{M}=1.08, \mathrm{AD}=0.54 \\
\text { Dent. Prof., } \mathrm{M}=0.62, \mathrm{AD}=0.37\end{array}$ & $\mathrm{U}=6,994, \mathrm{t}=-4.47, p<.001$ & $r=-0.281$ \\
\hline \hline
\end{tabular}

From Table 3, it is apparent that significant differences in the frequency of hedges, boosters, selfmentions and attitude markers are found between the learner and professional report corpora 
Crosthwaite, P., Cheung, LML \& Jiang, F. (2017). Writing with attitude: Stance expression in learner and professional dentistry research reports. English for Specific Purposes, accepted, to appear.

analysed. In each case, the learner data contains a significantly higher frequency of stance markers over the professionally-written reports, with a small effect size noted for attitude markers, medium effect sizes noted for hedges and boosters, and large effect sizes noted for selfmention. We now turn to the use of these features by section.

\subsection{Cross-corpus comparison by section: Hedging}

Figure 1 and Table 4 below show that the learner dentistry reports contain a significantly higher frequency of linguistic devices used for hedging compared to that of the professional dentistry reports. To correct for multiple testing here, Holm-Bonferroni Sequential correction is applied to the $p$ values, and Pearson $r$ effect sizes are reported for significant values.

Figure 1. Use of hedging devices in learner and professional reports (by section)

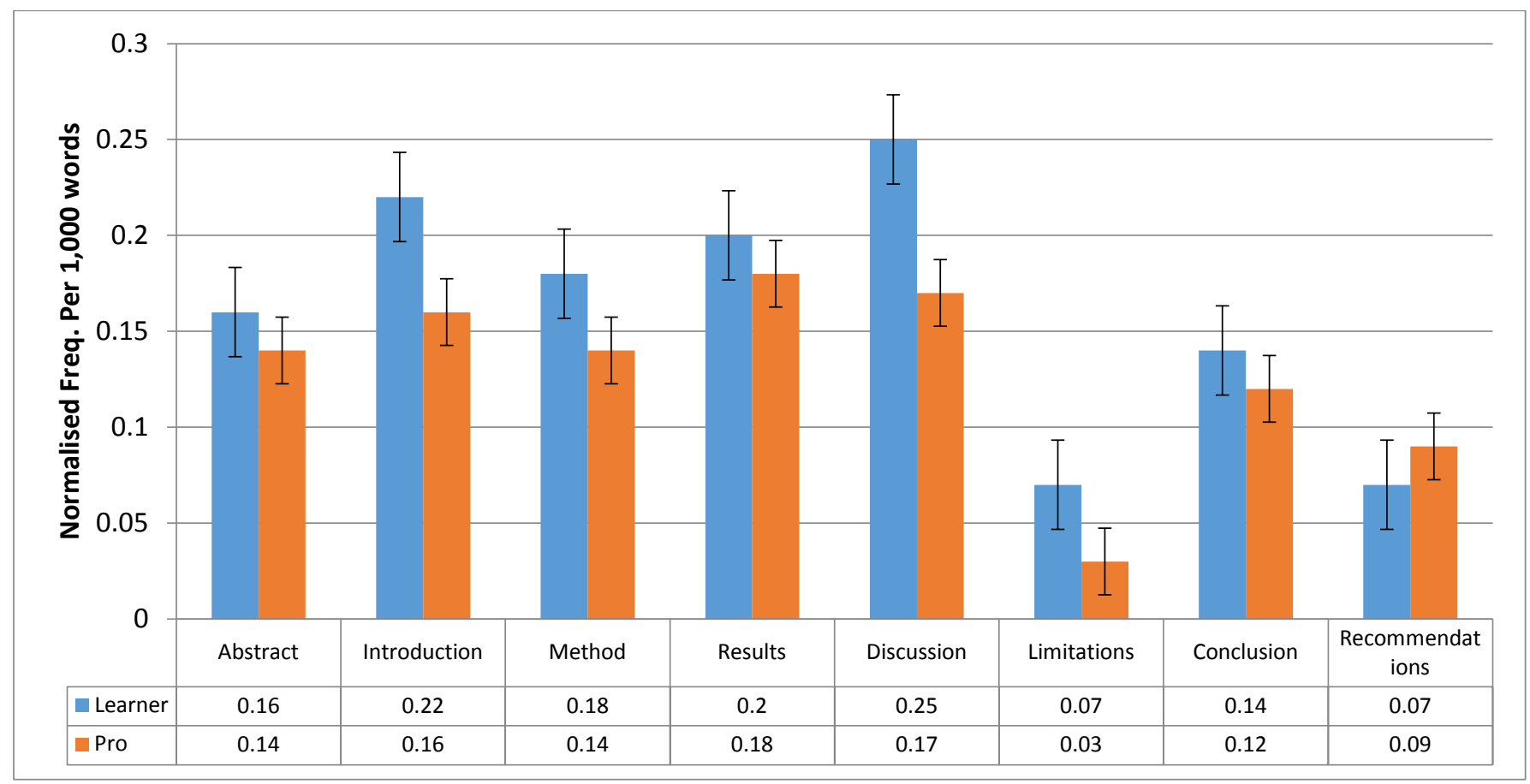


Crosthwaite, P., Cheung, LML \& Jiang, F. (2017). Writing with attitude: Stance expression in learner and professional dentistry research reports. English for Specific Purposes, accepted, to appear.

Table 4. Use of hedging devices in learner and professional reports (by section).

\begin{tabular}{|c|c|c|}
\hline Section & Mann-Whitney & Effect Size $(r)$ \\
\hline Abstract & $U=12820, Z=3.484, p<.001$ & 0.205 \\
\hline Introduction & $U=16763, Z=9.037, p<.001$ & 0.532 \\
\hline Method & $U=14960, Z=6.498, p<.001$ & 0.382 \\
\hline Results & $U=14375, Z=5.660, p<.001$ & 0.333 \\
\hline Discussion & $U=17279, Z=9.765, p<.001$ & 0.574 \\
\hline Limitations & $U=12561, Z=4.047, p<.001$ & 0.238 \\
\hline Conclusion & $U=12562, Z=3.154, p=.002$ & 0.186 \\
\hline Recommendations & $U=9041, Z=-2.091, p=.036$ & 0.123 \\
\hline
\end{tabular}

As with the results from the whole text analysis, the learner dentistry reports contain a significantly higher frequency of hedging devices than professional reports in each section, with the exception of the recommendations sections. The recommendations sections are significantly shorter in the professional corpus texts, perhaps leading to the significant difference between learner and professional corpora found for that section. For all other sections, notably the introduction (where the stance of others is likely to be hedged), the results / limitations / conclusion sections (where the stance of the writer(s) is likely to be hedged), and the discussion section (where the stance of both the writer(s) and/or others is likely to be hedged), the learner texts contain many more hedging devices. This is particularly notable in the introduction and discussion sections given the large reported Pearson $r$ effect sizes of $>.500$, with medium effect sizes reported for the method and results sections. With this in mind, an investigation of the 
Crosthwaite, P., Cheung, LML \& Jiang, F. (2017). Writing with attitude: Stance expression in learner and professional dentistry research reports. English for Specific Purposes, accepted, to appear.

wordings used for the hedging devices between the two corpora provide a potential explanation (Table 5).

Table 5 - Wordings for Hedges (Minimum LL 15.13, $p<.0001$ )

\begin{tabular}{ccclcc}
\hline Word & Freq. DL & Freq. PRO & $\begin{array}{c}\text { Specific to } \\
\text { DL vs. PRO }\end{array}$ & $\begin{array}{c}\text { Log } \\
\text { Likelihood }\end{array}$ & Effect Size (BIC) \\
\hline about & 720 & & & & \\
would & 1338 & 93 & DL & 381.24 & 367.43 \\
claimed & 323 & 345 & DL & 368.90 & 355.08 \\
quite & 220 & 30 & DL & 205.15 & 191.34 \\
could & 909 & 39 & DL & 141.14 & 127.33 \\
felt & 210 & 45 & DL & 82.63 & 91.91 \\
mainly & 259 & 47 & DL & 72.63 & 84.73 \\
usually & 218 & 52 & DL & 105.72 & 68.82 \\
generally & 191 & 62 & DL & 66.53 & 52.72 \\
might & 361 & 172 & DL & 36.35 & 22.54 \\
probably & 111 & 37 & DL & 24.23 & 10.42 \\
sometimes & 63 & 16 & DL & 20.07 & 3.26 \\
maybe & 38 & 6 & DL & 17.73 & 3.92 \\
------------ & $-------------~$ & ---------- & ------- & -17.44 & 3.63 \\
indicating & 0 & 78 & PRO & 132.87 & 119.06 \\
estimated & 1 & 69 & PRO & 50.94 & 94.36 \\
estimates & 1 & 53 & PRO & 81.44 & 67.63 \\
estimate & 23 & 61 & PRO & 30.88 & 17.07 \\
often & 132 & 175 & PRO & 25.42 & 11.61 \\
assumed & 11 & 38 & PRO & 24.78 & 10.97 \\
indicates & 32 & 63 & PRO & 21.53 & 7.72 \\
suggests & 27 & 56 & PRO & 20.72 & 6.91 \\
& & & & & \\
& & & & & \\
\hline
\end{tabular}

BIC effect size: 0-2: low effect, 2-6: positive evidence against the null hypothesis (H0), 6-10: strong evidence against H0, > 10: very strong evidence against H0 (Wilson, 2013)

Along with the differences in the frequency of hedging devices used between learner and professional corpora by section as reported in Table 4, Table 5 shows that across the whole texts, there are significant (i.e. $p<.0001$ ) differences in the wordings used for hedging between learner and professional texts. Professional writers appear to use the lemmas indicate, estimate and suggests frequently, with these lemmas most often used to hedge the author's own claims: 
Crosthwaite, P., Cheung, LML \& Jiang, F. (2017). Writing with attitude: Stance expression in learner and professional dentistry research reports. English for Specific Purposes, accepted, to appear.

(1) [Pro11.txt] Although the cost-effectiveness of preventive measures may vary according to the size of the community, the overall results indicating a favourable trend in the assessment of dental caries prevention programme from a societal perspective

(2) [Pro131.txt] This study also estimates the likely impact on DMFT indicators of excluding the $15 \%$ of children with lower capacity to understand a simple explanation

(3) [Pro43.txt] Thus overall there has been an increase in the ratio of the caries prevalence for the most deprived fifth to the middle fifth across the two survey years from 1.18 (53.8\%/45.5\%) in 2004-05 to 1.24 (52.4\%/42.1\%) in 2008-09. This suggests that there has been a widening of the inequalities gap in Wales

Learner writers, on the other hand, hedge the claims of others with claimed and felt, while hedging the reporting of behaviour with usually, generally, sometimes, and explicitly expressing uncertainty with might, probably, maybe:

(4) [Learner53.txt] Over three-quarters $(83 \%, 399)$ of the study participants claimed that they experienced an oral health problems in the past

(5) [Learner31.txt] Patients can usually come up with a multitude of excuses to avoid or escape from dental treatment, such as a lack of time or money

(6) [Learner57.txt] This in part may relate to the effects of drug abuse on caries experience or is maybe just a reflection of the underlying social background of the group

They are also more likely to express conditional epistemology via modals such as could and would, hedge numerical information with about, and attributive information with quite.

(7) [Learner18.txt] About one third of the people with SSc in this study showed a XI score equal to or more than 30. This could mean that SSc has a larger effect on some Chinese people with SSc in Hing Kong or more severe self-reported symptoms of dry mouth could be resulted from more severe scleroderma

(8) [Learner12.txt] Fifty six point four percent of private dental practitioners preferred an item-based payment method and about $90 \%$ of them were willing to provide oral examinations and scaling for the proposed scheme 
Crosthwaite, P., Cheung, LML \& Jiang, F. (2017). Writing with attitude: Stance expression in learner and professional dentistry research reports. English for Specific Purposes, accepted, to appear.

(9) [Learner19.txt] The participants were quite evenly distributed amongst the group according to relevant working experience, $41.4 \%$ of them had 5 years or less working experience while $31.7 \%$ of them had worked for more than 10 years

Professional writers, while less frequently hedging both their and others' claims, tend also not to hedge with adverbs and modals, instead using specific verbs to convey uncertainty or to be careful about expressing any claim made in the text. There was no correlation found between the date of the learner reports and the use of hedging devices, implying that, as yet, there has been little impact of any English language training on the use of such devices, or that the conditions under which the texts are produced are encouraging the learner writers to frequently hedge their claims.

\subsection{Boosters}

Figure 2 and Table 6 compare the frequency of boosting devices annotated between learner and professional reports.

Figure 2 - Frequency of boosting devices used between learner and professional reports 
Crosthwaite, P., Cheung, LML \& Jiang, F. (2017). Writing with attitude: Stance expression in learner and professional dentistry research reports. English for Specific Purposes, accepted, to appear.

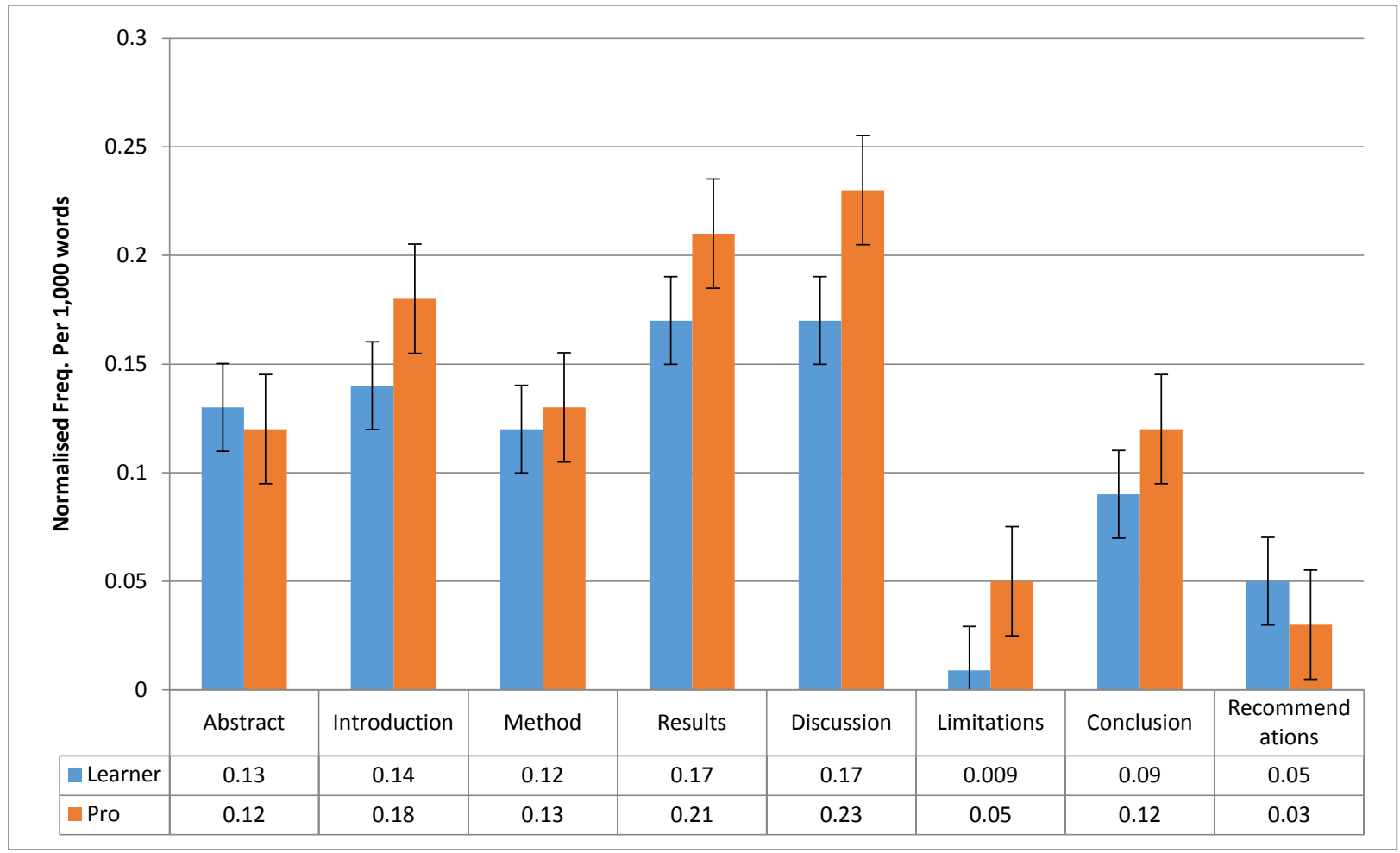

Table 6. Comparing the use of boosting devices in learner and professional reports (by section).

\begin{tabular}{|c|c|c|}
\hline Section & "Mann-Whitney & Effect Size $(r)$ \\
\hline Abstract & $\mathrm{U}=11043, \mathrm{Z}=0.964, \mathrm{p}=.546$ & \\
\hline Introduction & $U=14510, Z=5.864, p<.001$ & 0.345 \\
\hline Method & $U=12241, Z=2.694, p=.035$ & 0.158 \\
\hline Results & $U=15550, Z=7.322, p<.001$ & 0.431 \\
\hline Discussion & $U=16580, Z=8.778, p<.001$ & 0.516 \\
\hline Limitations & $U=12188, Z=4.139, p<.001$ & 0.243 \\
\hline Conclusion & $\mathrm{U}=12000, \mathrm{Z}=2.415, \mathrm{p}=.064$ & \\
\hline Recommendations & $U=9180, Z=-2.294, p=.066$ & \\
\hline
\end{tabular}

Pearson R Effect size interpretation, .10= ‘small’, .30= 'medium’, .50= 'large’, .70= 'very large’, Cohen (1988). 
Crosthwaite, P., Cheung, LML \& Jiang, F. (2017). Writing with attitude: Stance expression in learner and professional dentistry research reports. English for Specific Purposes, accepted, to appear.

The overall use of boosting devices by section between learner and professional writers is similar, with such devices used in the introduction (when boosting the claims of others) and results, discussion and conclusion sections (when boosting the claims of the authors). Surprisingly, when analysing the frequency of boosting devices by section (rather than across the entire text), professional writers utilise a significantly higher frequency of boosting devices in the introduction, results, discussion and limitation sections. This finding is apparently at odds with the finding above that, across the entire text, learner writers tend to boost their claims more frequently than professional writers. Medium to large effect sizes are noted for the introduction, results and discussion sections - particularly the discussion section, where the professional writers are boosting their own claims based on their research findings. We also note a significant negative correlation between the date the learner reports were produced and the use of boosting devices ( $r=-.200, p=.021$ ), which appears to suggest that the introduction of the ED curriculum over time may be responsible for the drop in boosting devices used.

Table 7 - Wordings for boosters (Minimum LL 15.13, p<.0001)

\begin{tabular}{|c|c|c|c|c|c|}
\hline Word & Freq. DL & Freq. PRO & $\begin{array}{l}\text { Specific to } \\
\text { DL or PRO }\end{array}$ & Log Likelihood & Effect Size (BIC) \\
\hline thought & 308 & 0 & DL & 342.65 & 328.84 \\
\hline found & 1120 & 628 & DL & 32.99 & 106.80 \\
\hline know & 216 & 28 & DL & 114.10 & 100.29 \\
\hline think & 96 & 0 & DL & 106.80 & 92.99 \\
\hline obvious & 50 & 0 & DL & 55.62 & 41.81 \\
\hline clear & 49 & 0 & DL & 54.51 & 40.70 \\
\hline believed & 132 & 37 & DL & 32.24 & 18.13 \\
\hline find & 125 & 37 & DL & 28.00 & 14.19 \\
\hline in fact & 76 & 21 & DL & 18.97 & 5.16 \\
\hline never & 138 & 55 & DL & 33.35 & $\begin{array}{l}5.16 \\
2.74\end{array}$ \\
\hline shows & 5 & 117 & PRO & 163.14 & 149.33 \\
\hline shown & 149 & 207 & PRO & 34.37 & 20.56 \\
\hline showing & 9 & 40 & PRO & 31.41 & 17.60 \\
\hline demonstrating & 0 & 12 & PRO & 20.44 & 6.63 \\
\hline demonstrated & 66 & 99 & PRO & 19.98 & 6.17 \\
\hline finding & 0 & 10 & PRO & 17.03 & 3.22 \\
\hline
\end{tabular}


Crosthwaite, P., Cheung, LML \& Jiang, F. (2017). Writing with attitude: Stance expression in learner and professional dentistry research reports. English for Specific Purposes, accepted, to appear.
establishing
0
9
PRO
15.33
1.52

BIC effect size: 0-2: low effect, 2-6: positive evidence against the null hypothesis (H0), 6-10: strong evidence against H0, > 10: very strong evidence against H0 (Wilson, 2013)

Despite the finding that professional writers appear to boost claims more frequently than seen in learner writing at the section level, there are clear differences in the wordings used between professional and learner writers in this regard (Table 7). Professional writers tend to use variations of the verbs show and demonstrate when boosting their and others' claims, focusing on the findings rather than their or others’ personal feelings or actions.

(10) [Pro43.txt] Taken together, the results from across England Scotland and Wales show that the trend for reducing caries prevalence and severity continues in this age group in all three countries

(11) [Pro21.txt] The results obtained from this study demonstrate that periodontal disease among people over 75 years of age is more prevalent and more severe in the Puerto Rican population than in the overall US population, or among US Hispanics of similar age

On the other hand, learner writers tend to consider their or others' thought processes via verbs such as thought, know, thinking, believed, their or others' actions via the use of find/found, and also point out 'apparent' truths via adjectives such as obvious, clear and adverbs such as in fact and never.

(12) [Learner15.txt] The majority of them (91/159) thought that they had no perceived dental problem and a small group of them (13/159) thought dental treatments cost too much

(13) [Learner42.txt] Since the proposed periodontal treatment needs of the study subjects are based on their CPI scores, it is not surprising to find that the treatment needs of the subjects in the above three studies were similar

(14) [Learner51.txt] From our survey findings, it is obvious that there is a need for dental health education programmes on dental trauma management to be delivered to the teacher trainees in Hong Kong 
Crosthwaite, P., Cheung, LML \& Jiang, F. (2017). Writing with attitude: Stance expression in learner and professional dentistry research reports. English for Specific Purposes, accepted, to appear.

\subsection{Self-mentions}

Figure 3 and Table 8 show the frequency of self-mentions in both the learner and professional dentistry reports.

Figure 3 - Frequency of self-mentions used between learner and professional dentistry reports

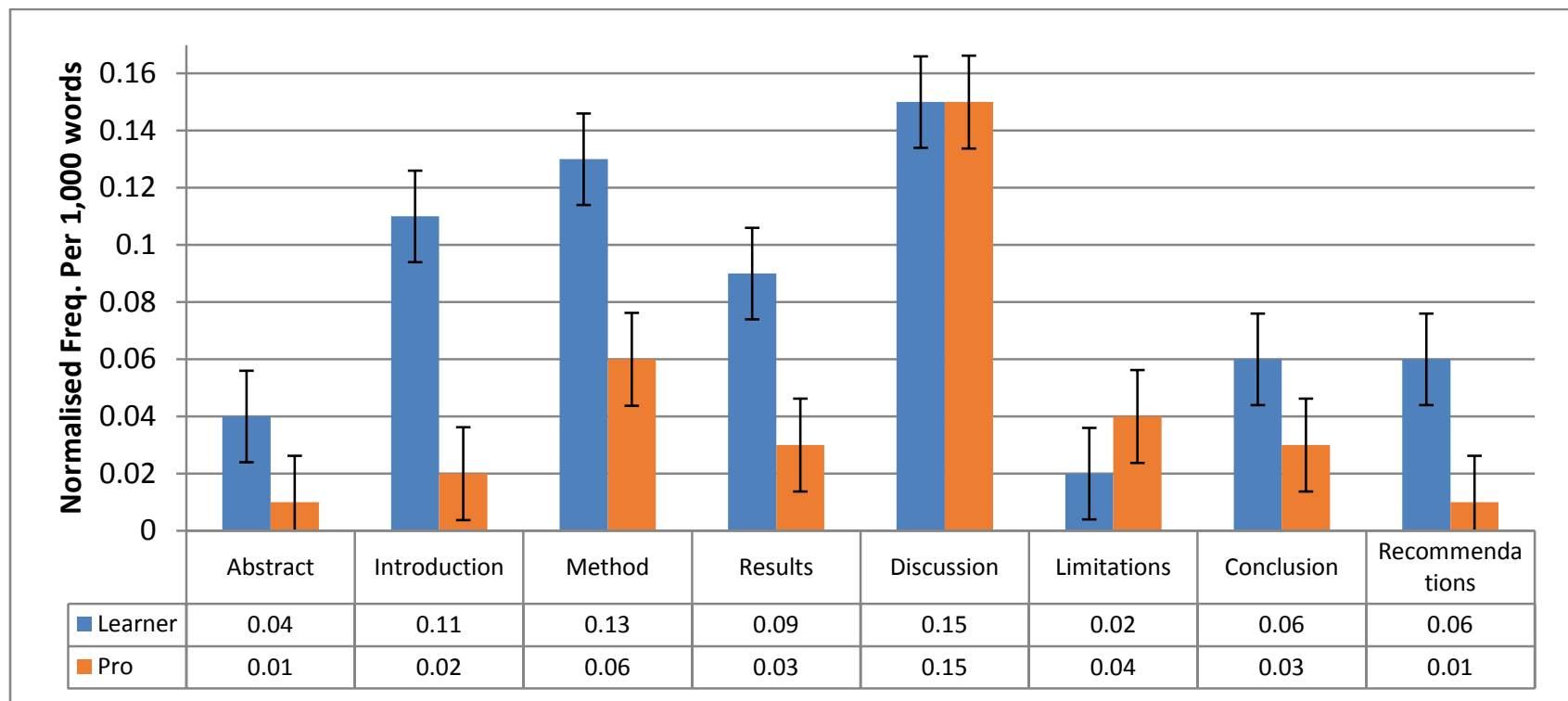

Table 8 - Comparing the use of self-mention in learner and professional corpora (by section).

\begin{tabular}{|c|c|c|}
\hline Section & "Mann-Whitney & Effect Size $(r)$ \\
\hline Abstract & $U=8759, Z=-3.681, p<.001$ & 0.217 \\
\hline Introduction & $U=5537, Z=-7.931, p<.001$ & 0.467 \\
\hline Method & $U=6731, Z=5.541, p<.001$ & 0.321 \\
\hline Results & $U=6966, Z=-5.725, p<.001$ & 0.337 \\
\hline Discussion & $\mathrm{U}=11334, \mathrm{Z}=1.369, \mathrm{p}=.342$ & \\
\hline Limitations & $\mathrm{U}=10951, \mathrm{Z}=1.331, \mathrm{p}=.342$ & \\
\hline Conclusion & $U=8206, \mathrm{Z}=3.991, p<.001$ & 0.235 \\
\hline Recommendations & $U=7106, Z=-6.496, p<.001$ & 0.381 \\
\hline
\end{tabular}


Crosthwaite, P., Cheung, LML \& Jiang, F. (2017). Writing with attitude: Stance expression in learner and professional dentistry research reports. English for Specific Purposes, accepted, to appear.

With the exception of the discussion and limitation sections, the learner dentistry reports contained a significantly higher number of self-mentions compared to those of professionally written texts. There is also a significant negative correlation between date of submission of the learner reports and the use of self-mention in the introduction ( $r=-.179, p=.039)$, method $(r=-.178$, $p=.041)$, results $(r=-.220, p=.011)$, conclusion $(r=-.199, p=.022)$ and recommendations sections ( $r=-.180, p=.039)$, suggesting that changes to the curriculum over time may be responsible for the drop in the use of these forms.

Table 9 - Wordings for self-mentions (Minimum LL 15.13=p<.0001)

\begin{tabular}{cccccc}
\hline \hline Word & Freq. DL & Freq. PRO & $\begin{array}{c}\text { Specific to } \\
\text { DL or PRO }\end{array}$ & Log Likelihood & Effect Size (BIC) \\
\hline & & & & & \\
Our & 1907 & 292 & DL & 869.53 & 882.72 \\
We & 1817 & 351 & DL & 699.39 & 685.57 \\
Us & 348 & 29 & DL & 232.08 & 218.27 \\
------------ \\
My & ----- & ------ & ----- & -38.37 & 18.17 \\
Author & 1 & 30 & PRO & 31.98 & \\
\hline \hline
\end{tabular}

BIC effect size: 0-2: low effect, 2-6: positive evidence against the null hypothesis (H0), 6-10: strong evidence against H0, > 10: very strong evidence against H0 (Wilson, 2013)

Learner writers frequently used the personal plural pronouns our, we and us (Table 9). One potential reason for this is that the learner dentistry reports were all group projects, while some 
Crosthwaite, P., Cheung, LML \& Jiang, F. (2017). Writing with attitude: Stance expression in learner and professional dentistry research reports. English for Specific Purposes, accepted, to appear.

of the texts in the professional corpus may have been written by single authors, although as both learner and professional texts have been anonymised, we are unaware of which papers were produced by single/multiple authors in either corpus. The use of our in the learner reports was mostly linked to mentions of the student group (LL=126.79, $p<.001$, BIC=102.98), or various words related to the project itself, including project $(\mathrm{LL}=354.89, p<.001, \mathrm{BIC}=341.08)$ :

[CHP0054.txt] Our group chose a daily life approach to deliver the message of oral health awareness.

[CHP00125.txt] Our project can provide information concerning the dental health status and treatment need of the children to the dentists serving the children there.

This stands in contrast to the use of our in professional written texts which tended to be used for mention of data $(\mathrm{LL}=18.74, p<.001$, $\mathrm{BIC}=4.92)$ in the discussion section:

[Pro0030.txt] There are reasons to believe that our data and the model have captured some of the social processes that were important for oral health development

The five most frequent verbs following we (except for the copula or modals) are found ( $n=100)$, decided $(n=40)$, recommend $(n=26)$, chose $(n=25)$, and think $(n=19)$, each of which convey a personal decision or suggestion made by the authors. Along with the increased use of us over the professional texts, it is apparent from the data that learner writers make considerable use of pronominal self-mention in almost every section of their reports.

\subsection{Attitude Markers}

Figure 4 - Frequency of attitude markers used between learner and professional dentistry reports 
Crosthwaite, P., Cheung, LML \& Jiang, F. (2017). Writing with attitude: Stance expression in learner and professional dentistry research reports. English for Specific Purposes, accepted, to appear.

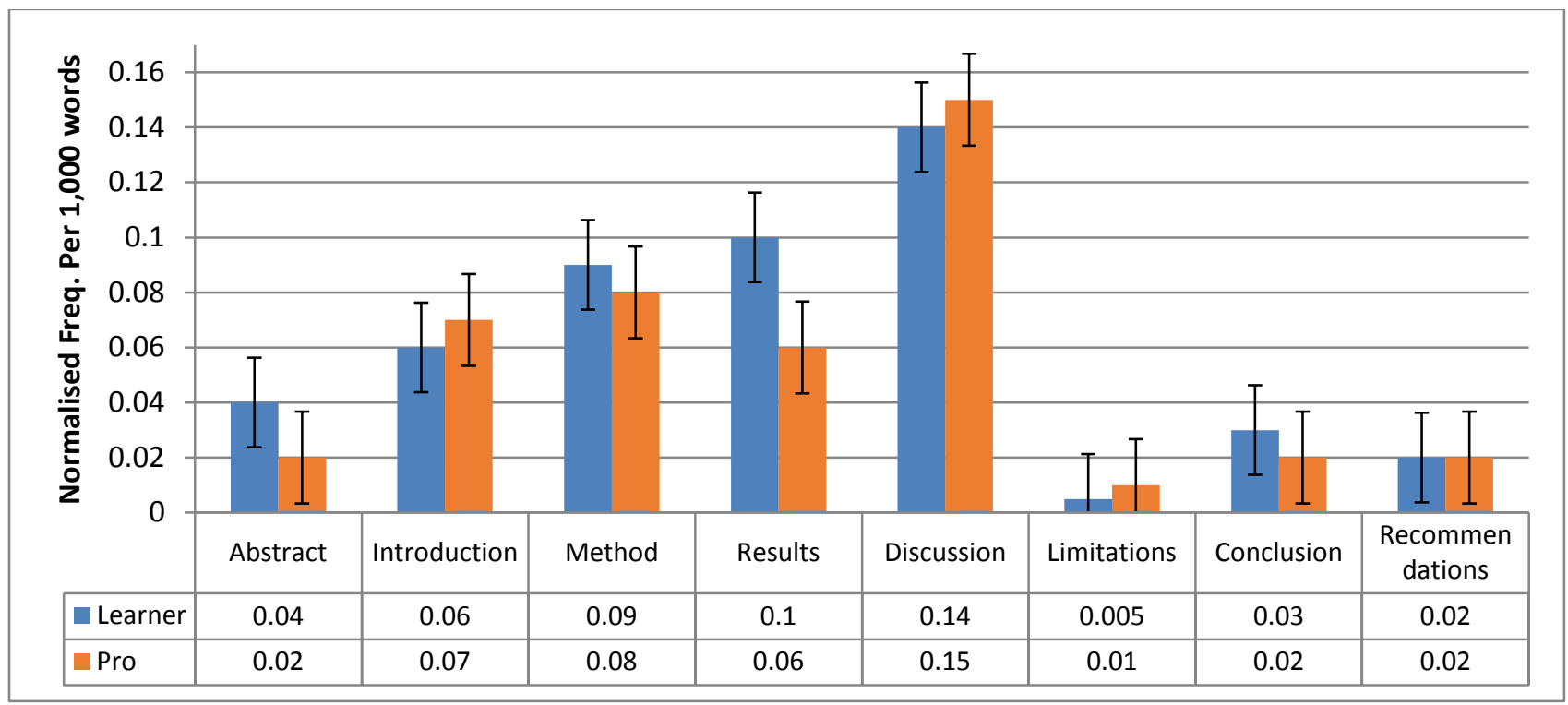

Table 10 - Comparing the use of attitude markers in learner and professional reports (by section).

\begin{tabular}{llc}
\hline \hline Section & Mann-Whitney & Effect Size $(r)$ \\
\hline Abstract & $\boldsymbol{U}=\mathbf{9 0 0 2 , Z = - 2 . 9 3 9 , p = . 0 2 4}$ & $\mathbf{0 . 1 7 3}$ \\
Introduction & $\mathrm{U}=10545, \mathrm{Z}=0.280, \mathrm{p}=1$ & \\
Method & $\mathrm{U}=10130, \mathrm{Z}=-.375, \mathrm{p}=1$ & \\
Results & $\boldsymbol{U}=\mathbf{8 4 8 3}, \mathrm{Z}=\mathbf{- 2 . 9 6 7 , \boldsymbol { p } = \mathbf { 0 2 4 }}$ \\
Discussion & $\boldsymbol{U}=\mathbf{1 2 4 1 3}, \mathrm{Z}=\mathbf{2 . 9 1 0 , p = . 0 2 4}$ & $\mathbf{0 . 1 7 5}$ \\
Limitations & $\mathrm{U}=10732, \mathrm{Z}=1.361, \mathrm{p}=.805$ & $\mathbf{0 . 1 7 1}$
\end{tabular}


Crosthwaite, P., Cheung, LML \& Jiang, F. (2017). Writing with attitude: Stance expression in learner and professional dentistry research reports. English for Specific Purposes, accepted, to appear.

Conclusion $\quad \mathrm{U}=9760, \mathrm{Z}=-1.401, \mathrm{p}=.805$

Recommendations $\quad \mathrm{U}=9923, \mathrm{Z}=-1.124, \mathrm{p}=.805$

Pearson R Effect size interpretation, .10= 'small’, .30= 'medium', .50= 'large', .70= 'very large', Cohen (1988).

The overall trend of attitude marker use across sections is largely similar between both groups of writers (Figure 4, Table 10). Namely, attitude markers are primarily used in the discussion section (where the writer expresses their attitude towards their own claims and findings) and are used relatively rarely in other sections. However, learner writers tend to more frequently produce attitude markers in the abstract and results sections than professional writers, while professional writers produce more attitude markers than learner writers in the discussion section, although the effect sizes for these reported differences are relatively small compared to the effect sizes found for other stance markers such as hedging and boosting. There is also a significant positive correlation between the time the learner report was produced and the use of attitude markers in the abstract section $(r=.196, p=0.24)$, with more recent reports making higher use of such markers than that of attitudinal markers found in earlier reports.

Table 11 - Wordings for attitude markers (Minimum LL 10.83=P<.001*, $15.13=p<.0001^{* *}$ )

\begin{tabular}{|c|c|c|c|c|c|}
\hline "Word & Freq. DL & Freq. PRO & $\begin{array}{l}\text { Specific to } \\
\text { DL or PRO }\end{array}$ & "Log Likelihood & Effect Size (BIC) \\
\hline Desirable & 88 & 12 & DL & $53.57 * *$ & 39.93 \\
\hline Agreed & 143 & 37 & DL & $26.58 * *$ & 12.76 \\
\hline Preferred & 105 & 31 & DL & $23.62 * *$ & 9.81 \\
\hline Interesting & 101 & 31 & DL & $21.28 * *$ & 7.46 \\
\hline Understandable & 18 & 1 & DL & $13.89 *$ & 0.08 \\
\hline Usual & 22 & 50 & DL & $21.02 * *$ & 7.21 \\
\hline
\end{tabular}

BIC effect size: 0-2: low effect, 2-6: positive evidence against the null hypothesis (H0), 6-10: strong evidence against H0, > 10: very strong evidence against H0 (Wilson, 2013) 
Crosthwaite, P., Cheung, LML \& Jiang, F. (2017). Writing with attitude: Stance expression in learner and professional dentistry research reports. English for Specific Purposes, accepted, to appear.

The use of desirable in the learner reports is typically used as a pre-modifier for noun phrases such as tooth colour / shape but such use was limited to just two learner reports and so may be treated as an outlier. The increased use of agreed and preferred can be explained through the increased use of surveys as the primary research method in the learner group projects, with this word used to refer to collated results:

[CHP0012.txt] Majority of students agreed that oral hygiene (81.6\%) and regular dental checkup (71.2\%) were important to them.

[CHP0096.txt] More than half of the respondents in all forms (61.7\%) preferred the programme to be an extension of the SCDS

The use of interesting typically preceded infinitive clauses with verbs such as know or note, with instances of note found in the results section and know found in the discussion section:

[CHP0122.txt] While none of the Chinese survey subjects was found to be edentulous in both jaws it is interesting to note that one Filipino subject aged 33 had lost all her teeth.

[CHP0058.txt] It would be interesting to know the attitudes of the dental professionals towards the application of alternative methods.

Agreed, preferred and interesting were not frequent attitude markers in the professionally written texts, with only usual featuring on the Log-Likelihood list for this corpus. Upon closer inspection the use of this word (as part of the phrase 'the usual reason for dentist attendance) is limited to a single file of the corpus and may also be discounted as an outlier. With this in mind, it appears that overall there are few differences in the frequency or wordings of attitude markers between the learner and professional dentistry reports by section, despite the significantly higher frequency of attitude marker use across the entire report by learner writers. 
Crosthwaite, P., Cheung, LML \& Jiang, F. (2017). Writing with attitude: Stance expression in learner and professional dentistry research reports. English for Specific Purposes, accepted, to appear.

\section{Discussion}

Our study aimed to see the extent to which student writers of research dentistry reports demonstrate evidence of enculturation into the profession in their writing, through a corpusbased comparison of stance features between learner and professionally-written texts. The focus of this discussion section includes how professional and learner writers manage the presentation of stance in their dentistry research reports, and the implications for pedagogy that arise from this comparison.

Regarding RQ1 (how professional and learner writers manage the presentation of stance in their respective dentistry research reports), the results of the corpus analysis have demonstrated significant differences between the two writer groups, evidenced in the varying frequencies and wordings of stance markers including hedging, boosting, self-mentions and attitude markers. Variation is exhibited across whole texts and between individual sections of said texts, alongside certain correlations between date of submission of the learner texts and the use of certain stance features suggestive of an effect of instruction. Learner writers are shown to very frequently hedge and boost their claims, appearing simultaneously cautious and confident when considering certain claims made by others or by themselves. Professional writers tend to use a narrower set of hedging and boosting verbs for these functions, unlike the wider range of adverbs and adjectives seen in the learner reports. Our findings for verbs for stance serve as an interesting comparison with that of Williams (1996) who found that professional medical writers also use certain reporting verbs to mark the move structures of both clinical and experimental studies. Learner writers are also significantly more likely than professional writers to include overt selfmention in their writing, and to convey theirs and others' attitude through adjectives and adverbs. Our findings for professionally-written texts are in line with those of Biber (2006) and 
Crosthwaite, P., Cheung, LML \& Jiang, F. (2017). Writing with attitude: Stance expression in learner and professional dentistry research reports. English for Specific Purposes, accepted, to appear.

Thompson and Hunston (2000) in terms of the prevalence of epistemic markers compared with those of attitudinal markers, and our findings also match Aull and Lancaster’s (2014) claim that developing academic writers frequently use boosters and hedges.

Regarding RQ2 (the extent to which student writers of PBL research final-year dentistry reports demonstrate evidence of enculturation into the dentistry profession in their writing), overall, one can claim from these results that learner writers of the dentistry reports exhibit a measured degree of enculturation into the profession as evidenced by the frequency, selection and functional use of stance features used in their PBL research reports, and that the collected works are all considered as successful group PBL dentistry research reports, receiving a passing grade. Learner writers of these dentistry reports are able to hedge and boost the claims of others and their own claims within each relevant section of their reports, albeit doing so using a wider range of devices than those seen in professional texts. Professional writers appear to rely on a smaller, limited set of stance markers perhaps more representative of the dentistry report genre, and use these features less frequently than learner writers in a smaller range of sections across a typical report structure. Our findings for professional writers are in line with Gross and Chesley's (2012) suggestion that experts reduce the frequency of hedges (and presumably also boosters, selfmention and attitude markers) used, in order to support perceived objectivity. Unlike professional writers, learner writers at this stage in their writing development tend to write with frequent overt mention toward the attitude of their stance, and also frequently insert themselves into their texts. However, for attitude markers at least, learner writers exhibit only minor differences in frequency and wordings of these forms compared with the writing of professionals who are active researchers (and expert writers) in their field. In short, despite the differences in the range and frequency of the stance markers used between learner and professional texts, the 
Crosthwaite, P., Cheung, LML \& Jiang, F. (2017). Writing with attitude: Stance expression in learner and professional dentistry research reports. English for Specific Purposes, accepted, to appear.

learner writers can be said - at their particular stage of interlanguage development - to be approximating many of the forms and functions associated with stance in professionally written research reports into their own group PBL final assessments, to the credit of both the instructors and the students themselves.

Regarding RQ3 (the implications for pedagogy regarding the outcome of the analysis of stance features across learner PBL research reports and those of professionally-written research papers), from the data, we suggest that teachers of dentistry-discipline-specific writing would best benefit from a process of further sensitising learners to the discursive norms of the research genre and rhetorical expectations of writing in the disciplines, beginning by narrowing the range of expressions used for hedging, boosting, self-mention and attitude markers to those preferred in the professionally-written research reports investigated in the present study. One of the most effective pedagogical suggestions is to expose students to professional research texts (such as those in the professional corpus) with explicit noticing of the particular stance expressions used by professional writers. By doing so, learner writers may consider themselves as writing with the 'right' attitude, narrowing the perceived gap between their own writing and that of the professional research genre. As a result of the present study, the use of particular wordings for stance markers in the professional corpus (including hedging, boosting, self-mentions and attitude markers) will be an explicit focus of the English-in-the-Discipline course in the next academic year. The corpus data obtained from the professional and learner corpora in this study have already been utilized in authentic language awareness tasks that form a significant part of the out-of-class learning component of the course. The tasks are in a diversified format, ranging from multiple-choice questions, gap-filling exercises to quizzes, and the tasks are all uploaded to the course's online platform for students' easy access and better integration of materials into the 
Crosthwaite, P., Cheung, LML \& Jiang, F. (2017). Writing with attitude: Stance expression in learner and professional dentistry research reports. English for Specific Purposes, accepted, to appear.

curriculum. Work is also underway to enhance data-driven learning by developing concordance software that allows the learner writers to access and consult the learner and professional corpora to better understand the linguistic features of research report writing. We have already noted an effect of time (and by implication instruction) in terms of the reduction of boosters and selfmention present in the learner texts, due to an increased emphasis on EAP and ED at the Institute over the last decade, and any future changes to pedagogy and materials suggested here should work to reduce and / or streamline the use of these devices to further represent professional norms. The continued success of the ED program and the dentistry degree in general in producing qualified, professional dentistry graduates shows that our efforts in 'learning to write' are also having an effect of 'writing to learn', although more work remains to be done in terms of further enculturating our learners into the profession before graduation.

A limitation of this research lies in a lack of meta-data about the participants, such as their scores on standardized English tests, scores from other modules on the dentistry curriculum, demographic information such as age/gender, etc., and given the group aspect of the learner reports, more information about how the group dynamic affects the writing process. We are also mindful that our professional corpus is comprised of published papers from only a single publication, which may have implications in terms of representativeness of the professional corpus across the dentistry field. While the use of a wider range of related journals might be suggested in future research, the selection of this particular journal was based on the need to find professionally-written research reports focusing specifically on the kind of community-based projects our students were involved in, with other journals in the field arguably more focused on experimental rather than community-focused research. 
Crosthwaite, P., Cheung, LML \& Jiang, F. (2017). Writing with attitude: Stance expression in learner and professional dentistry research reports. English for Specific Purposes, accepted, to appear.

In addition, our study concerns writing at an English as medium of instruction university in Hong Kong (where English is an official language), and so despite the general L1 Cantonese background of the majority of our students, the curriculum English language requirements, and problem-based approach are comparable to that of institutions in native English-speaking contexts. With this in mind, future research may seek to address the writing of dentistry students in Asian English-as-a foreign-language contexts such as Japan or Korea. Here, employment and/or promotion is still tied to publication, yet the English language requirements and expectations may be considerably lower. In such contexts, there is arguably a greater need for enhanced English-language training, with studies suggesting that the linguistic elements of journal papers are most problematic for professional writers in these contexts and that local scientists feel disadvantaged compared to those who graduated from English medium institutions (Cho, 2009). We also feel that it would be useful to compare students' written production longitudinally, from their EAP training in Year 1 to pre-/post-ED training in Year 5. This could be done qualitatively by exploring student's knowledge bases as suggested in Kuteeva and Negretti (2016), or quantitatively by employing longitudinal corpora as seen in Crosthwaite (2016). Doing so would allow instructors to triangulate the process of enculturation into the profession, potentially opening up the path to a criterion-referenced set of guidelines covering what students are expected to know and produce at each stage in their university lives, prompting intervention where students may be struggling to meet such requirements. We aim to collect such data in future research.

\section{References}

Aull, L. L., \& Lancaster, Z. (2014). Linguistic markers of stance in early and advanced academic writing a corpus-based comparison. Written Communication, 31, 151-183. 
Crosthwaite, P., Cheung, LML \& Jiang, F. (2017). Writing with attitude: Stance expression in learner and professional dentistry research reports. English for Specific Purposes, accepted, to appear.

Basturkmen, H. (2012). A genre-based investigation of discussion sections of research articles in dentistry and disciplinary variation. Journal of English for Academic Purposes, 11, 134-144.

Biber, D. (2006). University Language: A Corpus-based Study of Spoken and Written Registers. Amsterdam: John Benjamins.

Bley-Vroman, R. (1989). What is the logical problem of foreign language learning? In S. M. Gass \& J. Schachter (Eds.), Linguistic Perspectives on Second Language Acquisition (pp. 41-68). New York: Cambridge University Press.

Boughey, C. (1997). Learning to write by writing to learn: a group-work approach. ELT Journal, $51,126-134$.

Bruce, I. (2016). Constructing critical stance in university essays in English literature and sociology. English for Specific Purposes, 42, 13-25.

Carlson, D. M. (2000). A corpus-linguistic investigation of dental English. Journal of Dental Education, 64, 283-293.

Charles, M. (2004). The Construction of Stance: A Corpus-based Investigation of Two Contrasting Disciplines. (unpublished $\mathrm{PhD}$ thesis), University of Birmingham.

Cho, D.W. (2009). Science journal paper writing in an EFL context: The case of Korea, English for Specific Purposes, 28: 230-239, DOI:10.1016/j.esp.2009.06.002.

Cohen, J. (1988). Statistical Power Analysis for the Behavioral Sciences. $2^{\text {nd }}$ ed. New Jersey: Lawrence Erlbaum Associates.

Crawford J., Adami G., and Johnson B. (2007). Curriculum restructuring at a North American dental school: rationale for change. Journal of Dental Education, 71: 524-531.

Crosthwaite, P. (2016). A longitudinal multidimensional analysis of EAP writing: Determining EAP course effectiveness. Journal of English for Academic Purposes, 22, 166-178.

Dagneux, E., Denness, S. \& Granger, S. (1998). Computer-aided error analysis. System, 26, 163174.

Faculty of Dentistry, The University of Hong Kong. (2015). Regulations for the Degree of Bachelor of Dental Surgery (BDS).

Gilquin, G. (2000). The integrated contrastive model: Spicing up your data. Languages in Contrast, 3, 95-123.

Gross, A. G., \& Chesley, P. (2012). Hedging, stance and voice in medical research articles. In K. Hyland \& C. S. Guinda (Eds.), Stance and Voice in Written Academic Genres (pp. 85-100). London: Palgrave Macmillan.

Granger, S. (1996). From CA to CIA and back: An integrated approach to computerized bilingual and learner corpora. In Aijmer K. (ed.) Languages in Contrast. Text-based Crosslinguistic Studies (p. 37-51), Lund: Lund University Press

Granger, S. (2015). Contrastive interlanguage analysis: A reappraisal. International Journal of Learner Corpus Research, 1, 7-24.

Holmes, J. (1988). Doubt and certainty in ESL textbooks. Applied Linguistics, 9, 21-44.

Hu, G., \& Cao, F. (2015). Disciplinary and paradigmatic influences on interactional metadiscourse in research articles. English for Specific Purposes, 39, 12-25.

Hyland, K. (1999). Disciplinary discourses: Writer stance in research articles. In C. N. Candlin \& K. Hyland (Eds.), Writing: Texts, Processes and Practices (pp. 99-121). London: Longman. 
Crosthwaite, P., Cheung, LML \& Jiang, F. (2017). Writing with attitude: Stance expression in learner and professional dentistry research reports. English for Specific Purposes, accepted, to appear.

Hyland, K. (2000). Disciplinary Discourses: Social Interactions in Academic Writing. Edinburgh, UK: Pearson.

Hyland, K. (2002). Specificity revisited: how far should we go now? English for Specific Purposes, 21, 385-395.

Hyland, K. (2005). Stance and engagement: A model of interaction in academic discourse. Discourse Studies, 7, 173-192.

Hyland, K. (2016). Writing with attitude: Conveying a stance in academic texts. In E. Hinkel (Ed.), Teaching English Grammar to Speakers of Other Languages. New York: Routledge.

Hyland, K., \& Guinda, C. S. (2012). Stance and Voice in Written Academic Genres. England: Palgrave Macmillan.

Hyland, K., \& Jiang, F. (2016). Change of attitude? A diachronic study of stance. Written Communication, 33, 251-274.

Hyland, K., \& Tse, P. (2005). Hooking the reader: A corpus study of evaluative that in abstracts. English for Specific Purposes, 24, 123-139.

Jones, C., Turner, J., \& Street, B. V. (Eds.). (1999). Students Writing in the University: Cultural and Epistemological Issues. Amsterdam, John Benjamins.

Kuteeva, M. \& Negretti, R. (2016). Graduate students' genre knowledge and perceived disciplinary practices: Creating a research space across disciplines. Journal of English for Specific Purposes, 41, 36-49. DOI: 10.1016/j.esp.2015.08.004

Kumpf, E. P., \& Emanuel, J. T. (1996). "Stepping lively": reformatting the gap between student writing and professional writing. Technical Communication, 43, 163-171.

Lakoff, G. (1972). Hedges: A study in meaning criteria and the logic of fuzzy concepts. Chicago Linguistic Society Papers, 8, 183-228.

Lancaster, Z. (2014). Exploring valued patterns of stance in upper-level student writing in the disciplines. Written Communication, 31, 27-57.

Lancaster, Z. (2016). Expressing stance in undergraduate writing: Discipline-specific and general qualities. Journal of English for Academic Purposes, 23, 16-30.

Marco, M. J. L. (2000). Collocational frameworks in medical research papers: A genre-based study. English for Specific Purposes, 19, 63-86.

Martin, J. R. \& White, P. R. R. (2005). The Language of Evaluation: Appraisal in English. London: Palgrave Macmillan.

McGrath, L., \& Kuteeva, M. (2012). Stance and engagement in pure mathematics research articles: Linking discourse features to disciplinary practices. English for Specific Purposes, 31, 161-173.

Millar, N. and Budgell, B. S. (2008). The language of public health - a corpus-based analysis. Journal of Public Health, 16, 369-374.

Morse, Z., \& Nakahara, S. (2001). English language education in Japanese dental schools. European Journal of Dental Education, 5, 168-172.

Nesi, H., \& Gardner, S. (2012). Genres Across the Disciplines: Student Writing in Higher Education. Cambridge: Cambridge University Press.

O’Donnell, M. (2008). The UAM CorpusTool: Software for corpus annotation and exploration. In Proceedings of the XXVI Congreso de AESLA, Almeria, Spain (pp. 3-5). 
Crosthwaite, P., Cheung, LML \& Jiang, F. (2017). Writing with attitude: Stance expression in learner and professional dentistry research reports. English for Specific Purposes, accepted, to appear.

Pololi, L., Knight, S. and Dunn, K. (2004), Facilitating Scholarly Writing in Academic Medicine. Journal of General Internal Medicine, 19, 64-68. doi: 10.1111/j.1525-1497.2004.21143.x

Rayson, P. (2016). Log Likelihood Calculator. Retrieved from http://ucrel.lancs.ac.uk/people/paul/SigEff.xlsx

Rodis, O. M.M. , Barroga, E., Barron, J.P., Hobbs, J. Jayawardena, J.A., Kageyama, I., Kalubi, B., Langham,C., Matsuka, Y., Miyake, Y., Seki, N., Oka, H., Peters, M., Shibata, Y., Stegaroiu, R., Suzuki, K., Takahashi, S., Tsuchiya, H., Yoshida, T. and Yoshimoto, K. (2014). A proposed core curriculum for dental English education in Japan. BMC Medical Education, 14, 239.

Salager-Meyer, F. (1994). Hedges and textual communicative function in medical English written discourse. English for Specific Purposes, 13, 149-170.

Swales, J. M. (1990). Genre Analysis: English in Academic and Research settings. Cambridge: Cambridge University Press.

Taavitsainen, I. (2015). Medical case reports and scientific thought-styles. Revista de Lenguas para Fines Específicos, 17, 75-98.

Thompson, G., \& Hunston, S. (2000). Evaluation: An introduction. In S. Hunston \& G. Thompson (Eds.), Evaluation in Text: Authorial Stance and the Construction of Discourse (pp. 1-27). Oxford: Oxford University Press.

Vihla, M. (1999). Medical Writing: Modality in Focus. Amsterdam: Rodopi.

Williams, I. A. (1996). A contextual study of lexical verbs in two types of medical research report: Clinical and Experimental. English for Specific Purposes, 15, 175-197.

Wilson, A. (2013). Embracing Bayes factors for key item analysis in corpus linguistics. In M. Bieswanger, \& A. Koll-Stobbe (Eds.), New Approaches to the Study of Linguistic Variability. (pp. 3-11). Frankfurt: Peter Lang.

Yang, A., Zheng, S., \& Ge, G. (2015). Epistemic modality in English-medium medical research articles: A systemic functional perspective. English for Specific Purposes, 38, 1-10.

Young, S. S., Karr, A. (2011). Deming, data and observational studies. Significance, 8, 116-120

Appendix A - Stance markers annotated (Hyland, 2000)

\begin{tabular}{|l|l|l|l|}
\hline Attitude markers & Boosters & Self-mention & Hedges \\
\hline admittedly & actually & I & about \\
agree & always & we & almost \\
agrees & believe & apparent \\
agreed & melieved & our & apparently \\
amazed & beyond doubt & mine & appear \\
amazing & certain & us & appeared \\
amazingly & certainly & the author \\
appropriate & clear & the author's & approximately \\
appropriately & clearly & the writer & around \\
astonished & the writer's & assume \\
astonishing & decidedly & & assumed \\
astonishingly & definite & & certain amount \\
correctly & definitely & & certain extent \\
curious & demonstrate & & certain level \\
curiously & demonstrated & & claim \\
desirable & doubtless & & claimed \\
desirably & establish & & could \\
disappointed & established & couldn't \\
disappointing & evident & doubt \\
\hline
\end{tabular}


Crosthwaite, P., Cheung, LML \& Jiang, F. (2017). Writing with attitude: Stance expression in learner and professional dentistry research reports. English for Specific Purposes, accepted, to appear.

\begin{tabular}{|c|c|c|}
\hline $\begin{array}{l}\text { disappointingly } \\
\text { disagree } \\
\text { disagrees } \\
\text { disagreed } \\
\text { dramatic } \\
\text { dramatically } \\
\text { essential } \\
\text { essentially } \\
\text { even x } \\
\text { expected } \\
\text { expectedly } \\
\text { fortunate } \\
\text { fortunately } \\
\text { hopeful } \\
\text { hopefully } \\
\text { important } \\
\text { importantly } \\
\text { inappropriate } \\
\text { inappropriately } \\
\text { interesting } \\
\text { interestingly } \\
\text { prefer } \\
\text { preferable } \\
\text { preferably } \\
\text { preferred } \\
\text { remarkable } \\
\text { remarkably } \\
\text { shocked } \\
\text { shocking } \\
\text { shockingly } \\
\text { striking } \\
\text { strikingly } \\
\text { surprised } \\
\text { surprising } \\
\text { surprisingly } \\
\text { unbelievable } \\
\text { unbelievably } \\
\text { understandable } \\
\text { understandably } \\
\text { unexpected } \\
\text { unexpectedly } \\
\text { unfortunate } \\
\text { unfortunately } \\
\text { unusual } \\
\text { unusually } \\
\text { usual }\end{array}$ & $\begin{array}{l}\text { evidently } \\
\text { find } \\
\text { found } \\
\text { in fact } \\
\text { incontestable } \\
\text { incontestably } \\
\text { incontrovertible } \\
\text { incontrovertibly } \\
\text { indeed } \\
\text { indisputable } \\
\text { indisputably } \\
\text { know } \\
\text { known } \\
\text { must (possibility) } \\
\text { never } \\
\text { no doubt } \\
\text { obvious } \\
\text { obviously } \\
\text { of course } \\
\text { prove } \\
\text { proved } \\
\text { realise } \\
\text { realised } \\
\text { really } \\
\text { show } \\
\text { shown } \\
\text { sure } \\
\text { surely } \\
\text { truly } \\
\text { true } \\
\text { undeniable } \\
\text { undeniably } \\
\text { undisputedly } \\
\text { undoubtedly } \\
\text { without doubt } \\
\text { believes } \\
\text { demonstrates } \\
\text { finds } \\
\text { proves } \\
\text { realises } \\
\text { shows } \\
\text { showed } \\
\text { think } \\
\text { thinks } \\
\text { thought } \\
\text { ingule }\end{array}$ & $\begin{array}{l}\text { doubtful } \\
\text { essentially } \\
\text { estimate } \\
\text { estimated } \\
\text { feel } \\
\text { felt } \\
\text { frequently } \\
\text { from our perspective } \\
\text { generally } \\
\text { guess } \\
\text { in general } \\
\text { in most cases } \\
\text { in most instances } \\
\text { in our view } \\
\text { indicate } \\
\text { indicated } \\
\text { largely } \\
\text { likely } \\
\text { mainly } \\
\text { may } \\
\text { maybe } \\
\text { might } \\
\text { mostly } \\
\text { often } \\
\text { on the whole } \\
\text { ought } \\
\text { perhaps } \\
\text { plausible } \\
\text { plausibly } \\
\text { possible } \\
\text { possibly } \\
\text { postulate } \\
\text { postulated } \\
\text { presumable } \\
\text { probable } \\
\text { probably } \\
\text { relatively } \\
\text { roughly } \\
\text { seems } \\
\text { should } \\
\text { sometimes } \\
\text { somewhat } \\
\text { suggest } \\
\text { suggested } \\
\text { suppose } \\
\text { suspect } \\
\text { tend to } \\
\text { tends to } \\
\text { typical } \\
\text { typically } \\
\text { uncertain } \\
\text { uncertainly } \\
\text { unclear } \\
\text { unclearly } \\
\text { unlikely } \\
\text { usually } \\
\text { would } \\
\text { wouldn't } \\
\text { broadly } \\
\text { tended to } \\
\text { presumably } \\
\text { suggests } \\
\text { from this perspective } \\
\text { from my perspective } \\
\text { in my view } \\
\text { in this view } \\
\text { in our opinion } \\
\text { in my opinon } \\
\text { to my knowledge } \\
\end{array}$ \\
\hline
\end{tabular}


Crosthwaite, P., Cheung, LML \& Jiang, F. (2017). Writing with attitude: Stance expression in learner and professional dentistry research reports. English for Specific Purposes, accepted, to appear.

\begin{tabular}{|l|l|l|}
\hline & & fairly \\
& & quite \\
& & rather $x$ \\
argue \\
argues \\
argued \\
claims \\
& & feels \\
& & indicates \\
& & supposed \\
& & supposes \\
& suspects \\
postulates
\end{tabular}

